\title{
Speed Control of Separately Excited DC Motor Using Triac
}

\author{
Osman Ahmed Said Ahmed Mohamed ${ }^{1}$, Dalia Mahmoud ${ }^{2}$ \\ ${ }^{1}$ Deparment of Control, Faculty of Engineering, Al-Neelain University, Sudan \\ ${ }^{2}$ Assosciate Professor, Head of Department of Control, Faculty of Engineering, Al-Neelain University, Sudan
}

\begin{abstract}
The following method proposes speed control of separately excited DC Motor using semiconductor devices like TRIAC and DIAC Devices. It also explains how we can control the speed of separately excited dc motor for various purposes. There are different types of speed control of separately excited DC motor for example; field control and armature control method. Also the speed control of dc motor it may use in different applications, such as \{lathes, fans, pumps, disc and band saw drive requiring moderate, torques, Electric traction, high speed tools, etc\}.
\end{abstract}

Keywords: TRAIC, DIAC, DC Motor, Torque, Electric Traction

\section{Introduction}

Something that essential in the industrial applications to develop the motors drives to its high performance, in fact the high performance must have good dynamic speed command tracking and load regulating response. And for long time the motors in the electric traction have been a secondary means, because the D.C motor considered as a SISO system having torque/speed characteristics compatible with most mechanical loads. Which made it a controllable over a large way of speed and that is

been done throw the proper adjustment of its terminal voltage. But now a day the brushless D.C motors, induction motors, andsynchronous motors became the most common used in electric traction all over the world.

But also there is a persistent effort to make them act just like the D.C motors. Even Thoth and throw innovative design and control strategies we can arrive to the persistent that effort to make them act just like the dc motor. The Hence dc motors are always a good proving ground for advanced control algorithm because the theory is extendable to other types of motors.

There are many practical control problems we can face. issues (motor control issues), which are they:

1) Variable and unpredictable inputs.

2) Noise propagation along a series of unit processes.

3) Unknown parameters.

4) Changes in load dynamics.

Over all of these subjects to maintain the performance of the system at acceptable levels the conventional constant achieve feedback controller fails. But also the incorruption for feed forward in the fabricated neural networks is important for several reasons, which are:

1) The dynamical properties of the system.

2) In practice it may improve the performance.

They are mostly present in most nonlinear dynamical system and can be used to implement specific structures.

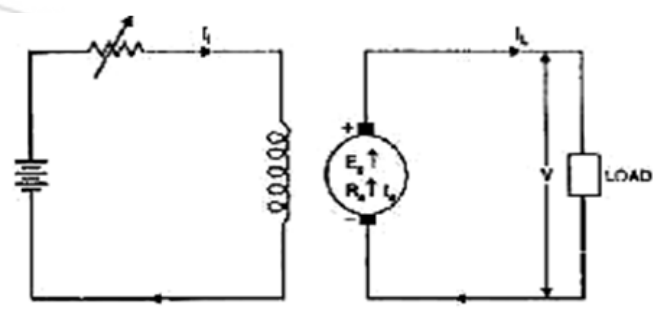

For the low cost of the Speed Control of DC Motor Using TRIAC. DC motors made it the most used in the industrial side, even more it is uncomplicated control structure, having a wide range of speed, and torque

The world usage of power increases every day with this increasing. The world works with a daily increased need for the power semiconductor units, by this need the speed control of DC motor is becoming sophisticated and precise.

A TRIAC is a bidirectional thyristor with three Terminals. Which are designed as:

1) MT1 (main terminal 1).

2) MT2.

3) gate by G.

In it by applying positive or negative voltage to the gate with respect to the terminal 1, the Triac can be turned on in each half cycle of the applied voltage. And for successful trigger a TRIAC, the Gate current must flow from the main terminal 2 side of the circuit below in figure 2 .
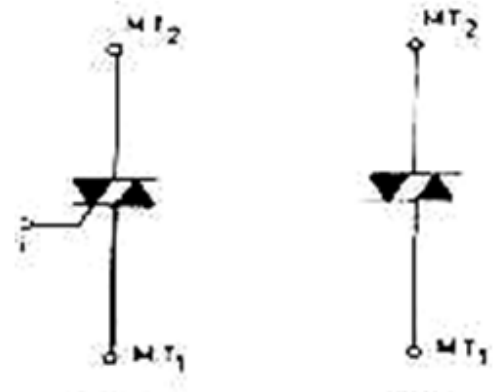

Triac 


\section{Voltage, Current and Power Equations}

We can find that the in the separately excited motor, armature and field windings are coming from two different dc supplies voltage. in this motor we can find:

Armature current Ia $=$ Line current $=\mathrm{IL}=\mathrm{I}$

Back emf developed, $\mathrm{Eb}=\mathrm{V}-\mathrm{I}$ Ra where $\mathrm{V}$ is the supply voltage and $\mathrm{Ra}$ being the armature resistance?

Power drawn from main supply, $\mathrm{P}=\mathrm{VI}$

Mechanical power developed, $\mathrm{Pm}=$ Power

input to armature $=$ power loss in armature $=\mathrm{VI}-\mathrm{I} 2 \mathrm{Ra}=\mathrm{I}$ $(\mathrm{V}-\mathrm{IRa})=\mathrm{Eb} \mathrm{I}$

\section{Speed Control}

Basically, the rotational speed of a DC motor is corresponding to the EMF in its coil (= the voltage applied to it minus voltage lost on its resistance), and the torque is corresponding to the current. Speed control can be achieved by variable battery tapping's, variable supply voltage, resistors or electronic controls. The direction of a wound field DC motor can be varied by reversing either the field or armature connections but not both. The effective voltage can be varied by inserting a series resistor or by an electronically controlled switching device made of thyristor, transistors, or, formerly, mercury arc rectifiers.

\subsection{Field Control}

The speed of DC motor can be controlled by variable factors in the following manners.

\subsubsection{Series-parallel}

Series-parallel control was the standard method of controlling railway traction motors before the advent of power electronics. An electric locomotive or train would typically have four motors can be classified in three different types:

- All four in series (each motor receives one quarter of the line voltage)

- Two parallel groups of two in series (each motor receives half the line voltage)

- All four in parallel (each motor receives the full line voltage) This provided three running speeds with minimal resistance losses. For starting and acceleration, additional control was provided by resistances. This system has been superseded by electronic control systems.

\subsubsection{Field Divertor Method}

The speed of a DC motor can be increased by field weakening. This is done by inserting shunt or diverter resistances in parallel with the field winding. When the field is weakened, the back-EMF reduces, so a larger current flows through the armature winding and this increases the speed. Field weakening is not used on itsown but in combination with other methods, such as series-parallel control below in figure 3 .

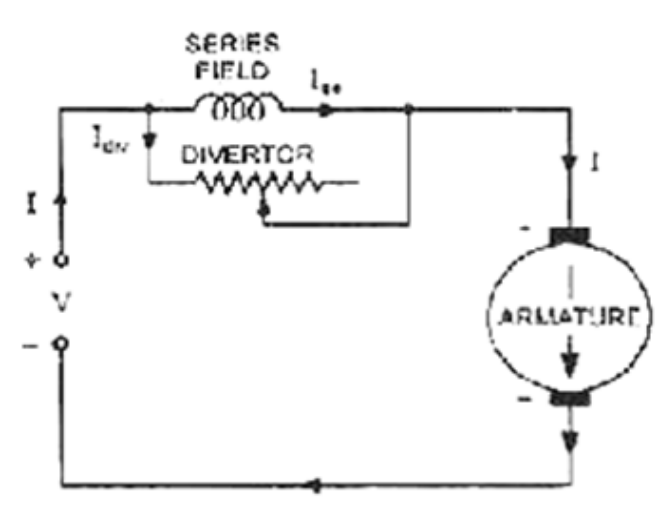

\subsubsection{Tapped field control}

This is another method of increasing the speed by reducing the flux and it is done by lowering number of turns of field winding through which current flows. In this method a number of tapping from field winding are brought outside. This method is employed in electric traction below in figure 4.

\subsection{Armature Control}

3.2.1 Armature resistance control method:

In this method armature circuit is provided with a variable resistance. Here the controlling resistance is connected directly in series with the supply to the motor as shown in the fig 5. Below

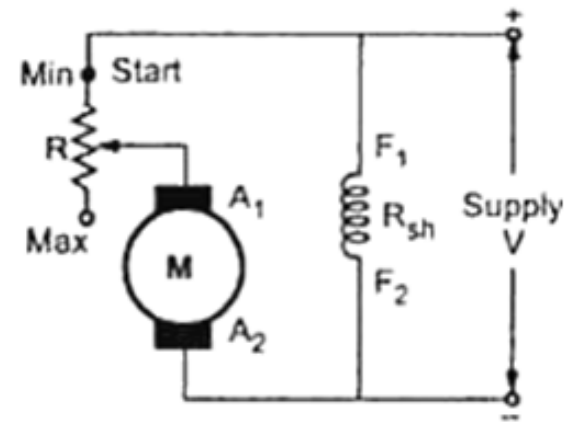

The power loss in the control resistance of dc series motor can be neglected because this control method is utilized for a large portion of time for reducing the speed under light load condition. This method of speed control is most economical for constant torque. This method of speed control is employed for dc series motor driving cranes, hoists, trains etc. 


\section{International Journal of Science and Research (IJSR) \\ ISSN (Online): 2319-7064}

Index Copernicus Value (2013): 6.14 | Impact Factor (2015): 6.391

\subsubsection{Shunted armature control}

The combination of a rheostat transforming the armature and a rheostat in series with the armature is involved in this method of speed control.

The voltage applied to the armature is varies by varying series rheostat $\mathrm{R} 1$. The exciting current can be varied by varying the armature transforming resistance $\mathrm{R} 2$. This method of speed control is not economical due to considerable power losses in speed controlling resistances. Here speed control is obtained over wide range but below normal speed below in figure 6 .
[3] Herman, Stephen. Industrial Motor Control. $6^{\text {th }}$ ed. Delmar, Cengage Learning, 2010.

[4] William H. Yeadon, Alan W. Yeadon. Handbook of small electric motors. McGraw-Hill Professional, 2001.

\subsubsection{Armature Terminal Voltage Control}

To fulfill The speed control of dc series motor, it should supply the power to the motor from a separate variable voltage supply. but unfortunately this way coasty so seldom it can be used below in figure 7 .
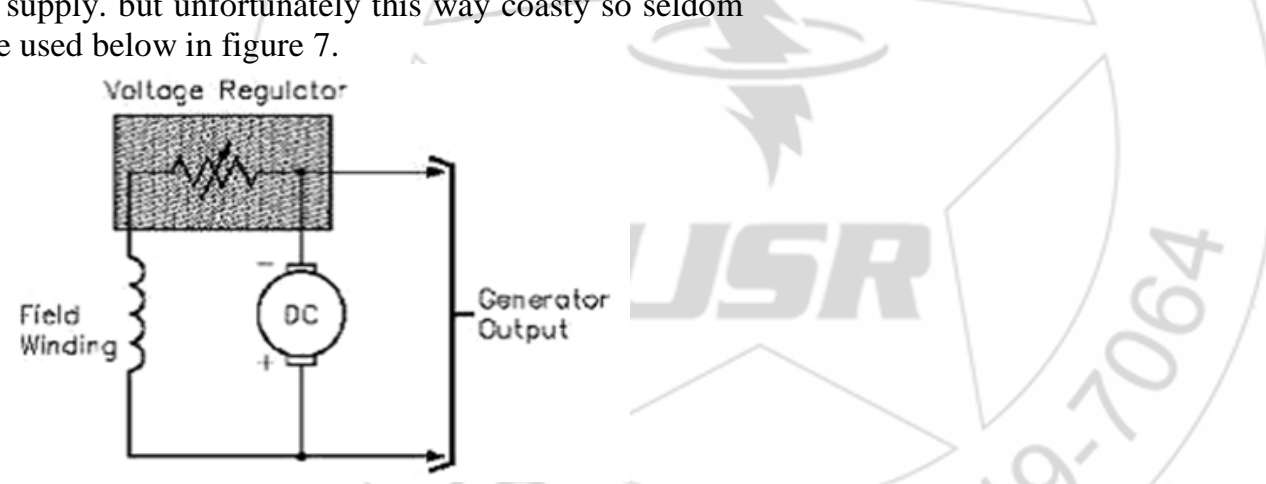

\section{Conclusion}

In this research I have tried to explain a bit about how to control the speed of a separately excited dc motor with the help of TRIAC and DIAC. also I had passed on the different types of methods and how can we use the speed control of dc motor.

\section{Applications}

This method (separately excited dc motors) are used in general in some of our daily machines like:

paper machines, diesel electric propulsion of ships, In steel rolling mills, etc.

\section{References}

[1] J.B.Gupta , publishers of engg. And computer books. 2010-11 edition.

[2] http://en.wikipedia.org/wiki/DC_motor 